\title{
ESTOLOMIMUS (COLEOPTERA, CERAMBYCIDAE, DESMIPHORINI): NOVAS ESPÉCIES E CHAVE
}

\author{
Ubirajara R. Martins ${ }^{1,3}$ \\ Maria Helena M. Galileo ${ }^{2,3}$
}

\begin{abstract}
ESTOLOMIMUS (COLEOPTERA, CERAMBYCIDAE, DESMIPHORINI): NEW SPECIES AND KEY. New species described from Brazil: Estolomimus maculatus (Minas Gerais and São Paulo), E. transversus (Espírito Santo), E. lichenophorus (São Paulo), and from Bolivia: E. abjunctus (Beni). A key to the species is added.
\end{abstract}

KEYWORDS. Cerambycidae, Desmiphorini, Estolomimus, taxonomy.

\section{INTRODUÇÃO}

O gênero Estolomimus foi estabelecido por BREUNING (1940) para única espécie do nordeste brasileiro, E. marmoratus Breuning, 1940. Martins \& GAlileo (1997), ao revisarem o gênero, sinonimizaram Neoestola Breuning, 1940 e Estolomimus, descreveram novas espécies e fizeram novas combinações; consideraram seis espécies, todas com distribuição na Mata Atlântica.

O material do Museu de Zoologia, Universidade de São Paulo, São Paulo (MZSP) e do Museu Nacional, Universidade Federal do Rio de Janeiro (MNRJ), enviado para estudo por M. A. Monné, contém novas espécies que são descritas; uma delas, E. abjunctus, amplia a distribuição do gênero para a Floresta Amazônica. Incluímos também nova chave para identificação das espécies.

\section{Estolomimus maculatus sp. nov.}

(Fig. 1)

Tegumento avermelhado. Vértice com pontos grandes, profundos e próximos. Lobos oculares superiores largos, com sete fileiras de omatídios, tão distantes entre si quanto a largura de um lobo. Lobos oculares inferiores grandes (quádruplo da área malar) ocupam

1. Museu de Zoologia, Universidade de São Paulo; Caixa Postal 42594; 04299-970 São Paulo, SP, Brasil.

2. Museu de Ciências Naturais, Fundação Zoobotânica do Rio Grande do Sul; Caixa Postal 1188; 90001-970 Porto Alegre, RS, Brasil.

3. Pesquisador $\mathrm{CNPq}$. 


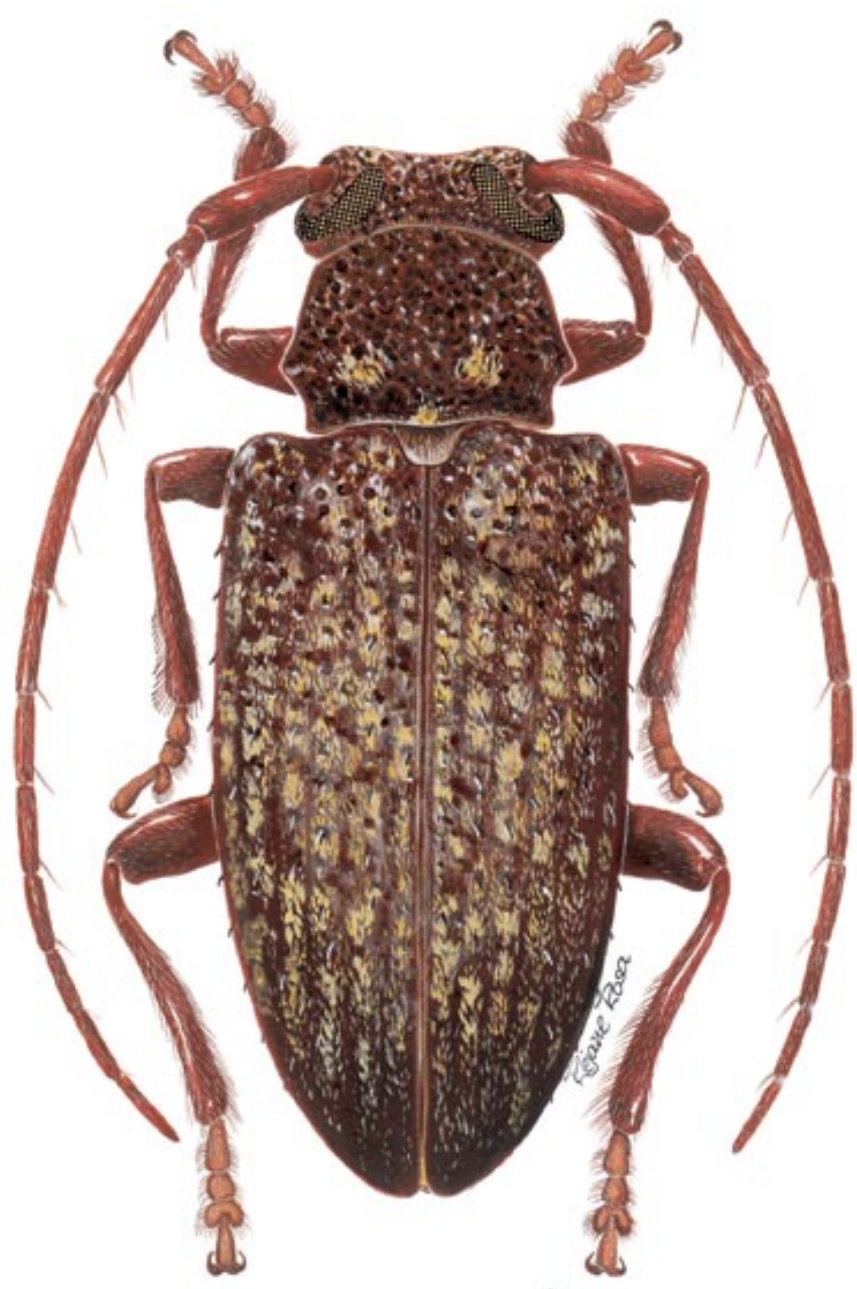

Fig. 1. Estolomimus maculatus sp. nov., holótipo $\subsetneq$, São Paulo, São Paulo, Brasil, comprimento, 5 mm.

quase todo lado da cabeça. Antenas não alcançam as extremidades dos élitros. Antenômeros com anéis estreitos de pubescência esbranquiçada na base e no ápice. Antenômero IV um terço mais longo do que o III e com o dobro do comprimento do V. Pronoto com três pequenos aglomerados de cerdas curtas: um à frente do escutelo e dois, um de cada lado, no terço posterior do pronoto. Poucas cerdas no restante da superfície pronotal. Élitros com manchas de cerdas amareladas (fig. 1) mais concentradas antes do meio; pontos do dorso, da base ao meio, não-organizados em fileiras. Lados do metasterno microesculturados. Fêmures e metatíbias unicolores, sem anel de tegumento amarelado. Lados do metasterno e urosternitos lisos e pubescentes. 
Dimensões em mm, respectivamente, $\delta /$ f. Comprimento total, 5,0/5,1; comprimento do protórax, 1,2/1,2; maior largura do protórax, 1,5/1,5; comprimento do élitro, 3,4/3,4; largura umeral, 1,9/2,0.

Material-tipo. Holótipo , BRASIL, São Paulo: São Paulo (Saúde), 3.I.1915, Melzer col. (MZSP). Parátipo Ő, Minas Gerais: Viçosa, XII.1944, Wygodzinsky col. (MZSP).

Discussão. O colorido de E. maculatus lembra o de E. distinctus Martins \& Galileo, 1997, mas E. maculatus tem lobos oculares superiores maiores e mais próximos; a borda anterior dos pontos do vértice e do pronoto não têm cerdas brancas; os élitros não têm faixa basal de pubescência amarelada; as manchas de pubescência amarelada dos élitros são mais numerosas; os pontos elitrais do dorso da região central não estão organizados em fileiras; os fêmures são unicolores, revestidos por pubescência uniforme, esbranquiçada; os lados do metasterno e os urosternitos têm pubescência uniforme e não são pontuados e as metatíbias são inteiramente avermelhadas. Em E. distinctus, os lobos oculares superiores têm cinco fileiras de omatídios e estão separados por distância equivalente ao dobro da largura de um lobo; os pontos do vértice e do pronoto têm uma cerda branca na borda anterior; a base dos élitros tem faixa transversal estreita de pubescência amarelada; as manchas amareladas dos élitros são menos numerosas; os pontos do dorso da região central dos élitros estão organizados em fileiras longitudinais; a metade apical dos fêmures tem pubescência amarelada entremeada por pontos contrastantes; os lados do metasterno e os urosternitos são pontuados e têm pubescência amarelada e as metatíbias têm anel central de tegumento amarelado.

\section{Estolomimus transversus sp. nov.}

(Fig. 2)

Tegumento castanho-avermelhado. Vértice e pronoto densamente pontuados, os pontos sem cerdas. Lobos oculares superiores com seis fileiras de omatídios, tão distantes entre si quanto a largura de um lobo. Lobos oculares inferiores com o quádruplo da área malar. Base e ápice dos antenômeros III-X revestidos por estreito anel de pubescência esbranquiçada. Pronoto sem áreas pubescentes. Escutelo revestido por densa pubescência amarelo-ouro. Élitros (fig. 2) com manchas de pubescência amarelo-ouro, mais ou menos organizadas em duas faixas transversais, que não tocam a sutura: uma no terço anterior, outra no terço posterior; mancha mais conspícua anteapical; pontuação entre as faixas organizada em fileiras longitudinais. Fêmures com pubescência esbranquiçada e sem pontos. Metatíbias unicolores. Metasterno e urosternitos I-IV microesculturados e sem pontos. Urosternito $\mathrm{V}$ ( $($ ) com alguns pontos.

Dimensões em mm, 9 . Comprimento total, 5,4-5,6; comprimento do protórax, 1,11,2; maior largura do protórax, 1,6-1,7; comprimento do élitro, 3,8-4,0; largura umeral, $2,3-2,4$.

Material-tipo. Holótipo q, BRASIL, Espírito Santo: Linhares (Parque Sooretama), X.1967, F. M. Oliveira col. (MNRJ). Parátipo $\uparrow$, mesmos dados do holótipo (MZSP).

Discussão. Estolomimus transversus apresenta as metatíbias unicolores como $E$. maculatus e difere pelos caracteres mencionados na chave. O padrão de colorido dos élitros (fig. 2) é característico. 


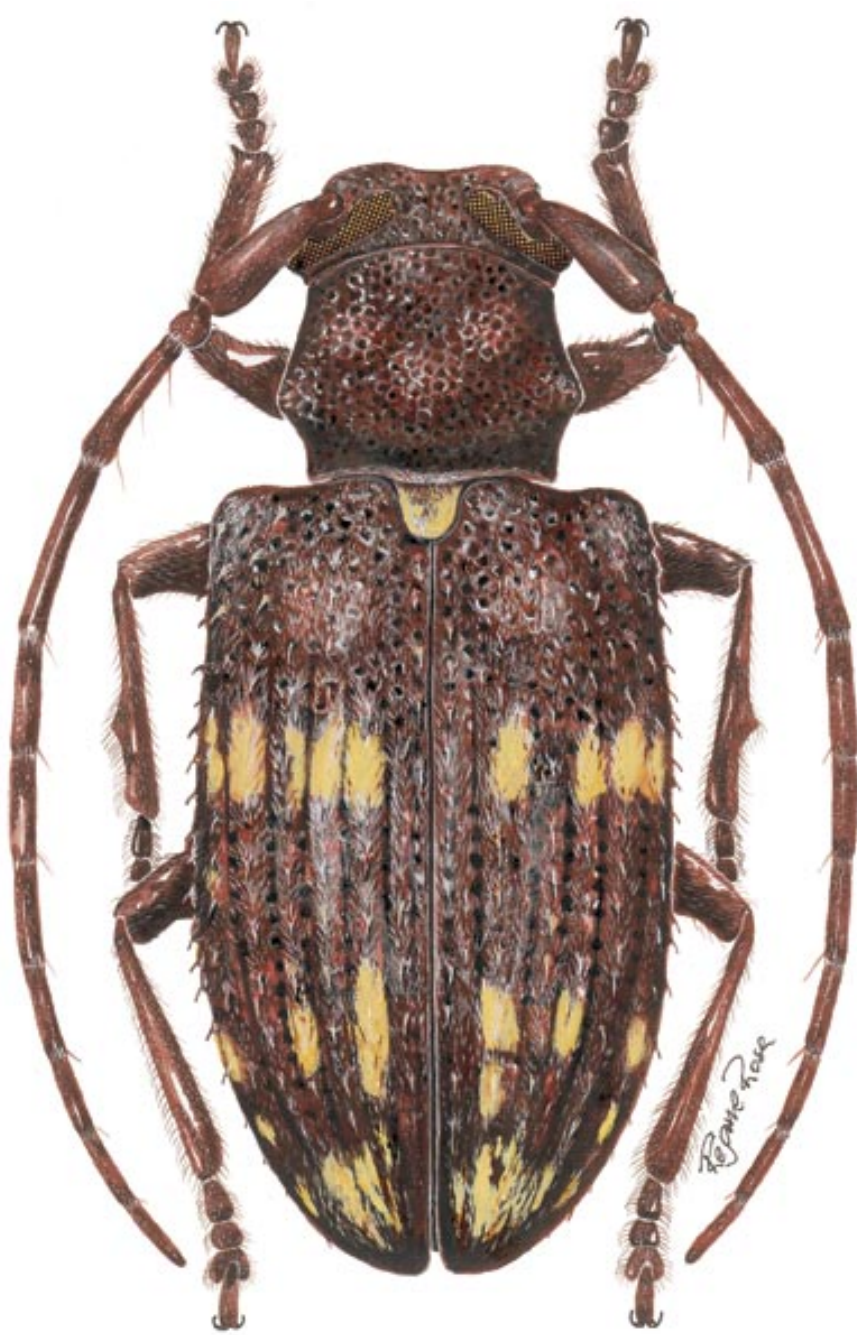

Fig. 2. Estolomimus transversus sp. nov., parátipo $\subsetneq$, Linhares, Espírito Santo, Brasil, comprimento total, 5,4 mm.

\section{Estolomimus abjunctus sp. nov.}

(Fig. 3)

Tegumento de maneira geral avermelhado, mais escuro na cabeça. Fronte densamente pontuada. Lobos oculares superiores com três fileiras de omatídios, tão afastados entre si quanto o dobro da largura de um lobo. Lobos oculares inferiores apenas mais longos do que a área malar. Antenas com tegumento amarelado: antenômeros III, VI, VIII, X, exceto no extremo apical, castanho-escuros; metade basal dos antenômeros 


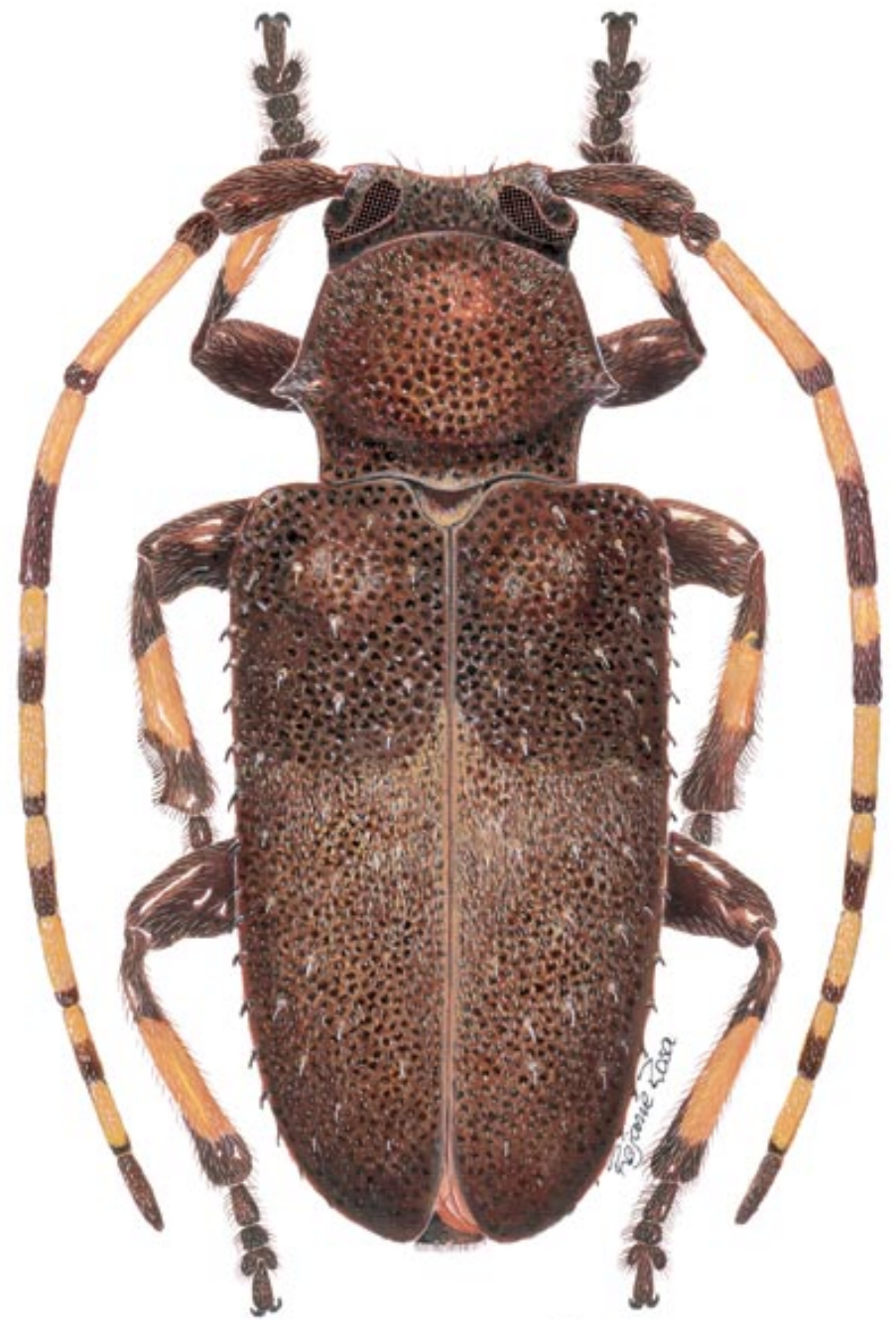

Figs. 3. Estolomimus abjunctus sp. nov., holótipo §, Rurrenabaque, Beni, Bolívia, comprimento 5,0 mm.

IV, V, VII e IX; antenômero XI inteiramente acastanhado. Escapo com 2/3 do comprimento do antenômero III. Metade posterior do pronoto com raras e pequenas manchas de pubescência clara. Élitros (fig. 3) com o terço anterior brilhante e os 2/3 apicais recobertos por escamas branco-amareladas; terço anterior praticamente sem pubescência. Mesepisternos com pontos grandes em toda superfície. Metasterno e urosternitos densamente pontuados em toda superfície com lados providos de pubescência amarelada. Tíbias com largo anel central, amarelado.

Dimensões em mm, 子. Comprimento total, 5,0; comprimento do protórax, 1,1; maior largura do protórax, 1,4; comprimento do élitro, 3,5; largura umeral, 1,9. 
Material-tipo. Holótipo ơ, BOLÍVIA, Beni: Rurrenabaque (175 m), X.1956, L. Peña col. (MNRJ).

Discussão. Estolomimus abjunctus caracteriza-se pelo colorido das antenas. O padrão de colorido dos élitros é semelhante ao de E. apicale Martins \& Galileo, 1997, mas E. abjunctus distingue-se, além do colorido das antenas, pelo pronoto com manchas raras e pequenas de pubescência clara; pela parte recoberta por pubescência clara ocupar os dois terços apicais dos élitros; pela presença de pubescência amarelada na metade apical dos fêmures, nos lados do metasterno e dos urosternitos.

\section{Estolomimus lichenophorus sp. nov.}

(Fig. 4)

Tegumento de maneira geral avermelhado. Antenas com tegumento amarelado na metade basal do artículo IV; nos antenômeros VI, VIII, X, menos no ápice; XI com anel central castanho. Cabeça revestida por pubescência esbranquiçada. Lobos oculares superiores com quatro fileiras de omatídios, tão distantes entre si quanto o dobro da largura de um lobo. Lobos oculares inferiores pouco mais longos que a área malar. Protórax quase inteiramente revestido por pubescência esbranquiçada. Élitros com uma faixa transversal de pubescência esbranquiçada que reveste a declividade basal; o restante do terço anterior tem escassa pilosidade; os 2/3 apicais (fig. 4) revestidos por pubescência esbranquiçada com tonalidade discretamente esverdeada. Lados do metasterno revestidos por pubescência esbranquiçada entremeada por raros pontos unicolores.

Dimensões em mm, respectivamente $3 / 4$. Comprimento total, 4,4-5,2/6,0; comprimento do protórax, 1,0-1,1/1,2; maior largura do protórax, 1,4-1,5/1,6; comprimento do élitro, 3,0-3,8/4,4; largura umeral, 1,8-2,0/2,4.

Material-tipo. Holótipo ơ', BRASIL, São Paulo: Peruíbe, I.1945, Coleção H. Zellibor (MNRJ). Parátipos: São Paulo (Cantareira), ỏ, 10.IV.1941, Coleção H. Zellibor (MZSP); (Jabaquara), f, 4.X.1953, Coleção H. Zellibor (MNRJ).

Discussão. E. lichenophorus assemelha-se à E. curtus (Breuning,1940), mas se distingue principalmente pela pubescência corporal que é mais densa e, nos élitros, tem colorido branco-esverdeado. Em E. curtus a pilosidade da base dos élitros é mais amarelada.

Chave para as espécies de Estolomimus

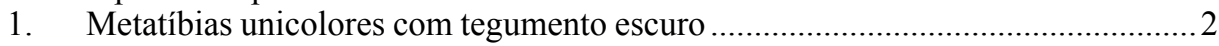

Metatíbias com anel central de tegumento branco ........................................... 7

2(1). Antenômero III unicolor com tegumento escuro ................................................ 3

Antenômero III bicolor, amarelado na base .................................................... 6

3(2). Élitros em grande parte recobertos por pubescência esbranquiçada, amarelada ou

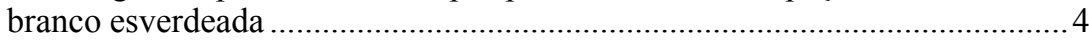

Élitros sem grandes áreas cobertas por pubescência clara ................................... 5

4(3). Pubescência elitral esverdeado-clara; sem faixa de pubescência branca no meio dos élitros; (fig. 4). Brasil (São Paulo) E. lichenophorus sp. nov. Pubescência elitral amarelada; com faixa de pubescência esbranquiçada no meio dos élitros. Brasil (Espírito Santo ao Rio Grande do Sul) 


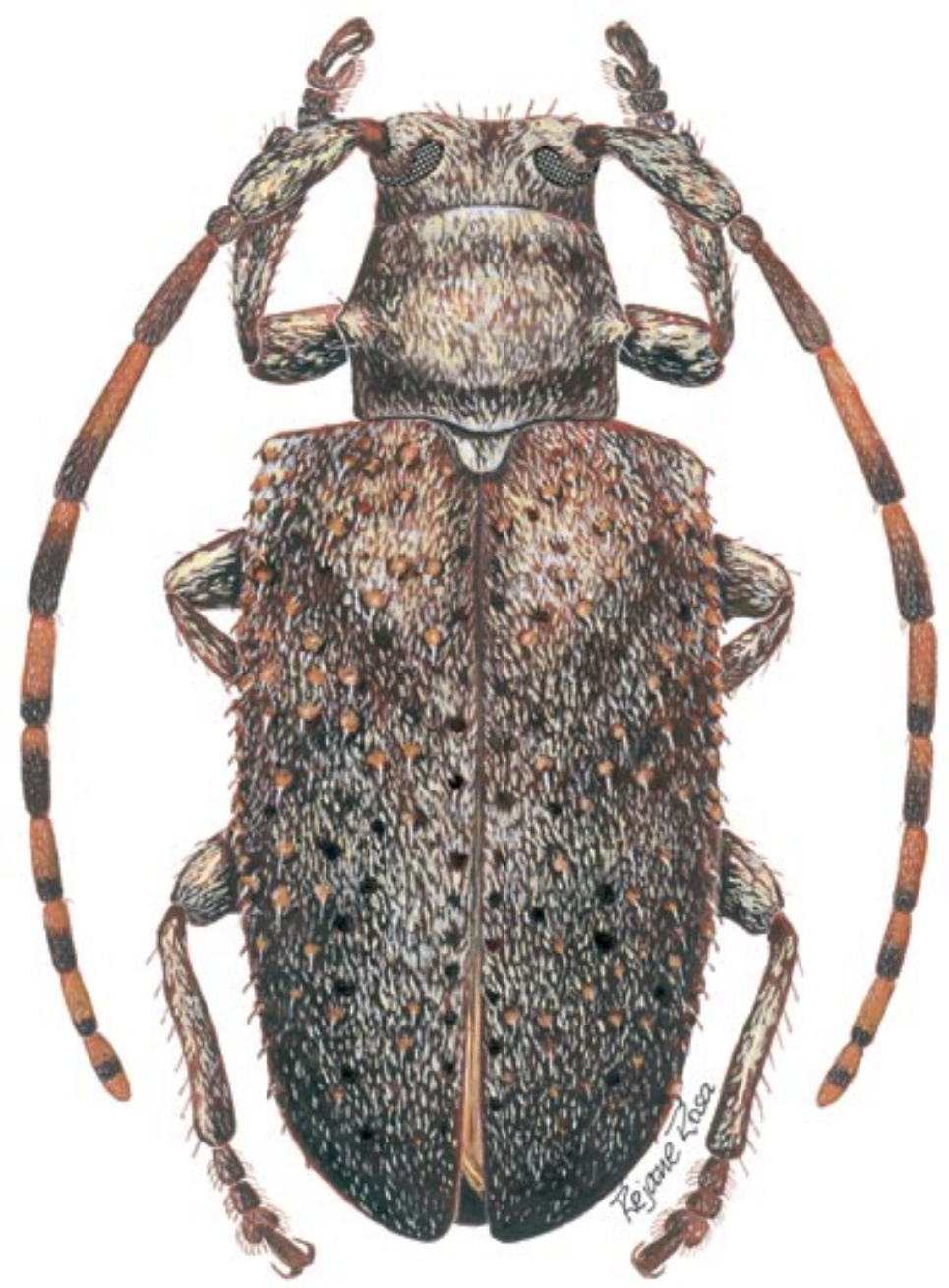

Fig. 4. Estolomimus lichenophorus sp. nov., parátipo \&, São Paulo (Jabaquara), São Paulo, Brasil, comprimento 6 mm.

5(3). Escutelo revestido por escassa pubescência esbranquiçada; pontos do dorso da metade apical dos élitros não-organizados em fileiras; pubescência elitral branco-amarelada organizada em manchas em toda a metade anterior; (fig. 1). Brasil (Minas Gerais, São Paulo) .................................. E. maculatus sp. nov. Escutelo revestido por densa pubescência amarelo-ouro; pontos do dorso da metade apical dos élitros organizada em fileiras; pubescência elitral amarelo-ouro mais concentrada em duas faixas transversais e estreitas (fig. 2). Brasil (Espírito Santo) E. transversus sp. nov. 
6(2). Metade apical dos élitros salpicada de máculas de pubescência alaranjada; anel basal do antenômero III com tegumento branco. Brasil (Santa Catarina)

E. pulvereus Martins \& Galileo, 1997

Metade apical dos élitros marmoreada por pubescência amarelada; terço basal do antenômero III com tegumento alaranjado. Brasil (Ceará)

E. marmoratus Breuning, 1940

7(1). Pontos da região central do dorso dos élitros não-organizados em fileiras; metade ou terço apical dos élitros revestidos por pubescência densa, branco-amarelada ou amarelada.

Região dorso-central dos élitros com pontos alinhados em fileiras longitudinais; metade apical dos élitros com manchas pequenas de pubescência amarelada. Brasil (Espírito Santo) .......................... E. distinctus Martins \& Galileo, 1997

8(7). Antenômero III amarelado com ponta preta; áreas de pubescência clara na metade posterior do pronoto, raras e pequenas; na região apical dos élitros inicia-se pouco à frente do meio; (fig. 3). Bolívia E. abjunctus sp. nov. Antenômero III preto com anel basal amarelo; metade posterior do pronoto com áreas mais numerosas de pubescência branco-amarelada; a pubescência clara na região apical dos élitros inicia-se depois do meio

9(8). Base dos élitros concolor com o terço anterior, sem faixa transversal de pubescência; terço apical recoberto por pubescência compacta, esbranquiçada; lobos oculares superiores largos, com 6 fileiras de omatídios; lobos oculares inferiores com o dobro do comprimento da área malar. Brasil (Espírito Santo)

E. apicale Martins \& Galileo, 1997

Base dos élitros com faixa transversal de pubescência amarelada interrompida pelos pontos; terço apical dos élitros recoberto por pubescência amarelada, compacta; lobos oculares superiores estreitos, com 4 fileiras irregulares de omatídios; lobos oculares inferiores com a metade do comprimento da área malar. Brasil (Rio de Janeiro a Santa Catarina) ......................... E. solidus (Breuning, 1940)

Agradecimentos. Ao colega M. A. Monné (MNRJ) pelo empréstimo de material; a Rejane Rosa (Museu de Ciências Naturais, Fundação Zoobotânica do Rio Grande do Sul) pela execução das figuras.

\section{REFERÊNCIAS BIBLIOGRÁFICAS}

Breuning, S. 1940. Novae species Cerambycidarum. VIII. Folia zool. hydrobiol., Riga, 10:37-85.

Martins, U. R. \& Galileo, M. H. M. 1997. Revisão dos gêneros Pseudestola Breuning, Estolomimus Breuning e Euestola Breuning (Coleoptera, Cerambycidae, Lamiinae, Desmiphorini). Revta bras. Zool., Curitiba, 14(1):99-112.

Recebido em 07.11.2001; aceito em 27.03.2002 